\title{
Bilingualism on display: The framing of Welsh and English in Welsh public spaces
}

\author{
N I K O L A S COUPLA N D \\ Centre for Language and Communication Research, \\ Cardiff University, Colum Drive \\ Cardiff CF10 3EU, Wales, United Kingdom \\ coupland@cardiff.ac.uk
}

\section{A B S T R A C T}

This article develops an interpretive perspective on public displays of bilingualism. Photographic data from contemporary Wales illustrate how public bilingual-Welsh and English - displays are organized in different frames, reflecting historically changing language-ideological priorities and more local symbolic markets. In institutionally driven displays, the Welsh language is framed as an autonomous code in parallel with English, displacing an earlier pattern of representing Welsh subordinated to English norms. In other frames Welsh is constructed as the only legitimate heartland language, or as an impenetrable cultural curiosity. In the most open and least institutionalized frame, Welsh is displayed as part of a culturally distinctive but syncretic cultural system. These framing contests dramatize deeper tensions that surface in attempts to revitalize minority languages under globalization. (Wales, Welsh, bilingualism, language display, language ideology, linguistic landscapes, metaculture)*

\section{N T R O D U C T I O N}

Some facets of what are nowadays called linguistic landscapes were anticipated in Eastman \& Stein's (1993) theorizing of language display. For example, Eastman \& Stein focused on speakers displaying some element of a foreign linguistic repertoire, specifically NOT in order to accommodate other groups' norms, except in a transient and ambiguous way - an early account of crossing, in the sense of Rampton (1995, 2006). Eastman and Stein moved on to consider patterns of public written signage, such as commercial street signs in Bogota. They commented on how Colombian tradespeople branded their businesses through ethnosymbolic displays of English, such as The Coffee Shop, in order to invoke an aura of cosmopolitanism (1993:196).

Language display is a valuable orienting concept for the analysis of public bilingualism of the sort I deal with in this article - widely available signs, notices, and T-shirts featuring Welsh and English text in contemporary Wales. Texts of this sort are central parts of the Welsh bilingual LINGUISTIC LANDSCAPE (LL), and to that extent the present 
study contributes to the rapidly accelerating field of LL research (cf. Scollon \& Scollon 2003; Gorter 2006; Backhaus 2007, 2009; Shohamy \& Gorter 2009; Jaworski \& Thurlow 2010a; Shohamy, Ben-Rafael, \& Barni 2010). But it may be useful to distinguish "displayed" from "landscaped" bilingualism. In what follows, I draw on several valuable insights from LL research but without developing my own study within what I take to be mainstream LL assumptions and methods. Public language, treated as display, is market-driven, designed to attract symbolic capital in particular semiotic and cultural economies that are increasingly globalized. The displaying of bilingualism is a planned projection of social values and hierarchies, including ideological values attaching to language varieties and language situations. My present interest is to understand selective types of bilingual display in Welsh public spaces as the entextualization of competing language ideologies - ideologies of bilingualism that have specific historical underpinnings but that are still influential in contemporary Wales.

Goffman's (1974) frame analysis strengthens the account of language display. Although Goffman's main interest was in the shifting organizational premises according to which social interaction takes place, frame analysis has been taken up as a productive analytic perspective in countless social and institutional arenas. My argument is that displays of bilingualism are organized according to particular framing premises that stand in tension with each other, and sometimes in blatant mutual opposition. I suggest that public displays of Welsh and English in Wales are organized within five different frames or sets of framing premises. Each frame supports a distinctive conception of "bilingual Wales", and of how Welsh and English sit within it. Language policy and planning discourses in Wales currently valorize (and indeed dictate) bilingual displays organized around one particular set of premises - what I refer to as THE FRAME OF PARALLEL-TEXT BILINGUALISM. This is the currently dominant institutional frame whose displayed texts have, sometimes literally, overwritten earlier ones that presumed English cultural dominance. But other frames are in evidence too, reflecting different social and economic pressures and opportunities on Welsh in globalized markets.

In the following section I explore theoretical relationships among language display, linguistic landscaping, and frame analysis in more detail. I then briefly describe the changing status of Welsh in Wales and the main language policy/ planning initiatives being pursued in this connection. In the main section of the article I illustrate and analyse each of the five frames in turn. Finally, I comment on how these competing visualizations of bilingualism relate to language revitalization in Wales, and consider how language display may have particular salience in projecting local values in more global markets.

L A N G U G E D I S P A Y, F R A E A N A Y S I , A N D I N G U I T I L A N D C A P E S

Building on Eastman and Stein, we can say that language display is AGENTIVE, oBJECTIFYING, and CUMULATIVE. A publicly displayed bilingual text, for example, a 
directional road sign or a public information notice in Wales, comes to exist in its social environment through a series of institutional decisions and practices. LL texts that are described as "top-down" (e.g. Backhaus 2007, 2009) have this history of institutional agency, for example, when there is a national governmental prescription (as there is in Wales) that road signs should identify Welsh towns and cities in two languages, where alternative Welsh and English versions are available. (As we see below, these designations are less clear than they appear.) Any given pattern of bilingual signage of the sort that LL researchers might survey comes about through agentive decisions - sometimes overt governmental ones, sometimes more locally and individually based.

Somewhat similar observations can, surprisingly enough, be made in relation to NATURAL landscapes, which provide the metaphor for LINGUISTIC landscapes (Gorter 2006; Coupland 2010a). Adam suggests that physical features in the natural landscape may provide "a record of reality-generating activity" (Adam 1998:54; Coupland 2010a:78). She is thinking of how, for example, a prevailing wind direction results in patterns of lichen growth on trees, or how trees themselves may be permanently bent away from the wind, and this observation then becomes productive for understanding landscapes of other sorts. Cultural geographers have made similar claims when they have theorized what they call cultural landscapes. Citing Lewis (1979), and attributing the original expression of this perspective to Lewis, Schein (1997:661) argues that "The cultural landscape provides us with a series of sedimentary layers of social accretion, each cultural stratum reflecting particular ideological origins, intentions and contexts." In this view, a cultural landscape is agentively and cumulatively produced. Language display contributes to these processes when particular languages, and languages displayed in particular relationships to each other, are sedimented into public spaces, differently over time.

Within the tradition of LL research, Spolsky (2009) and many others have pointed to agentive display processes. Echoing Eastman and Stein's Bogota example, Curtin (2009) analyses "vogue or display English" in Taipei. Coulmas says that LL is "a cultural scene, formed by interested agents whose motivations and intentions... must be reckoned with in the analysis" (2009:23). Leeman \& Modan (2009:332) consider LLs to be "ideologically charged constructions." Lou (2009) brings this same emphasis to her analysis of the Washington, DC Chinatown as "cultural text." Kallen (2010) supports Scollon \& Scollon's discourseanalytic perspective on language displays in public spaces, arguing that we need to be sensitive to the indexical functioning of public signage as a form of dialogue between producers and consumers. Shohamy \& Waksman (2009:321) propose a view of LL as "an arena through which various agendas are being battled, negotiated and dictated." Jaworski \& Thurlow's (2010a) preference for the concept of "semiotic" over "linguistic" landscape has to do with their concern to account for the interplay between linguistic and visual meaning in landscape texts, but they also use the term as shorthand for a discursive and performative theorizing of space and place. 
All of these sources confirm that there is no necessary separation between LL and language-display perspectives. All the same, the idea persists that patterns in the LL index the cultures in which they exist, and specifically that the density of a language's presence in the LL will index its level of ethnolinguistic vitality. This was the principal claim in Landry \& Bourhis's (1997) study introducing the LL concept, and it theorizes the landscape more as a pattern of usage rather than as a contested field of performative display. In the case of Wales, it is reasonable to interpret the increased public visibility of Welsh alongside English as an index of enhanced efforts to revitalize Welsh, but this is too sparse an account. A display perspective allows us to interpret visible bilingualism not as a correlate of, but as a STYLIZATION of, ethnolinguistic vitality (Coupland 2007). Jaworski \& Thurlow (2010b:11) cite Jan Blommaert's argument that politics in general can be seen as a "struggle to entextualize authoritatively," and the ways in which Welsh is displayed in Wales quite clearly arise from particular political stances, and from DIFFERENT stances that are concurrently in play. Jaworski \& Thurlow therefore prefer to treat semiotic landscapes as "scopic regimes" that impose preferred visualizations of the social world and erase others, and this is the perspective I adopt here too.

When we are dealing with community languages as objectified displays, the ideological loading of texts is likely to have METACULTURAL significance, that is, when a cultural practice has the potential to define the culture in which it functions (Urban 2001; Kirshenblatt-Gimblett 2004; Coupland \& Garrett 2010). Public signs attached to commercial or administrative premises, often carrying visual images, logos, and self-referential labels, are very obviously meta-level devices (Coupland \& Jaworski 2004). Place names displayed at the margins of countries, cities, towns, districts, or streets - what Kallen (2010) calls "portals"-performatively constitute the boundaries that they physically mark. When it comes to "language culture," outside of governmental and legal edicts defining a zone as being, for example, "officially bilingual," public displays of more than one language do not definitively constitute the bilingual status of the environment. Rather, a particular display convention ASSERTS Or PROPOSES a version of ethnolinguistic arrangements and the "shape" of a bilingual culture. It may posit equal status and resources between languages, or imply an unproblematic, parallel co-existence between languages and social groups. It may posit hierarchical relations between languages and groups. It may challenge the legitimacy of a code and its idealized users, and so on. Bilingual displays are therefore moves in evolving discourses of cultural definition. They feature as part of "the dialectic between performance and its wider sociocultural and political-economic context" (Bauman \& Briggs 1990:61).

Goffman's frame analysis perspective, and its legacy in later theorizing of framing, help to clarify metacultural language-display processes. At the heart of Goffman's idea of framing is participants' understanding of the organizational premises of symbolic action. Utterances and texts are articulated within particular contextual assumptions, including assumptions about participant roles and goals, 
communicative genres, and norms. Interpretive contexts may differ, however, opening up the possibility of frame conflict or misunderstandings about which frame is operative. A familiar example is when boisterous physical action can be entered into as play, but interpreted as hostility. Frames have finite temporal currency, one frame giving way to another over time. Frames can relate to very local understandings of social contexts, or to broad cultural assumptions about communication. For the analysis of language displays in public, these considerations invite us to look beyond a distributional account of "which languages appear where," to identify the ideological presuppositions according to which particular display types were or are rationalized.

In a detailed review Scheff suggests that Goffman's frame analysis opens a perspective on "how the microscopic world of words and gestures is linked to the largest social structures" (2005:384), and this movement between text organization and ideological structures is a central quality of metacultural displays. An individual text can bring into play a raft of cultural presuppositions, as in Eastman and Stein's example of the ethnosymbolic use of an English shop sign in Bogota. The value of the display for the shop owner relies on a particular frame being in place, one in which the global value of English is already presumed. Consumers will be attracted to the shop only if they appreciate these same values, if their actions are motivated within the presumed frame.

Scheff develops the idea of frame cumulativity, which he points to in Goffman's original account. Scheff refers to "recursive structures of awareness" (2005:375), when social actors in some circumstances need to become aware of others' levels of awareness (Scheff suggests that spying and love relationships are the defining cases of recursive mutual awareness). But the general point is that communicative acts are liable to be structured as progressive, cumulative reframings, more or less radical, of organizational premises. As Scheff also points out, recognizing what frame is operative and how it may have shifted will often be a social, group-level process rather than an individual one (which differentiates the concept of frame from otherwise overlapping, more cognitively oriented concepts such as "knowledge schema"). Goffman did not consider reframings over historical rather than interactional time in his (1974) book, although he does explicitly acknowledge historical and cultural dimensions of frames in a later source. ${ }^{1}$

For Goffman frames were not entirely abstract interpretive resources. He wrote that "we seem to like to employ some sort of physical externalization of our frames" (1981:64). In interpersonal interaction, an intended frame may be cued by some gestural or paralinguistic means. But publicly visible texts also make meaning in multiple semiotic dimensions, drawing on spatial, typographical, and other visual styling resources. Key in Goffman's sense is a constitutive part of a frame, referring to the tenor of a communicative act, for example, serious versus playful, or assertive versus solicitous. A frame can be re-keyed, for example, through overlaying humor or irony on the ideational content of an utterance or text. But text-based language displays often cue or key their frames in these ways too, and they are not restricted 
to the po-facedness of institutionalized signage. Key proves to be important in distinguishing some of the five frames I analyse in Wales.

THE DEMOGRAPHIC AND POLICY CONTEXT OF B IL INGU A L W A LES

Strong, committed, and ambitious language policy and planning initiatives are being carried forward by the National Assembly for Wales. The Assembly, which came to adopt the title of the Welsh Assembly Government, is a semi-autonomous parliament that was devolved from the Westminster/London government in 1998. Through its current language policy, it seeks to consolidate and extend the reversal of a long-term decline in the numbers of Welsh speakers in Wales. Evidence from the decennial census - an extremely blunt instrument - showed a steady pattern of declining use of Welsh in Wales, from 50\% in 1901 to $36.8 \%$ in $1931,26 \%$ in 1961 to $18.9 \%$ in 1981 . This was followed by an impressive and widely celebrated increase from $18.7 \%$ in 1991 to $20.5 \%$ in 2001 (C. H. Williams 2001; Aitchison \& Carter 2004; Coupland \& Aldridge 2009).

A key planning document, Iaith Pawb ['Everyone's Language']:2 A National Action Plan for a Bilingual Wales, was published in 2003 as the centrepiece of the devolved Assembly's language revitalization policy, which itself stood as one of the Assembly's major achievements in its first term of office. The document had wide cross-party support but was strongly sponsored by the Assembly's former First Minister, Rhodri Morgan. Iaith Pawb has focused language policy over recent years, consolidating the demands of the 1993 Welsh Language Act, ${ }^{3}$ principally to "deal with the public on the basis of equality between Welsh and English." Iaith Pawb clarified the role of Bwrdd Yr Iaith Gymraeg (The Welsh Language Board), charged with monitoring "language schemes" (promoting Welsh-language services to the public) across the whole of the public sector in Wales. It also introduced new targets for the revitalization of Welsh, including a five percentage-point increase - to $26 \%$ of the overall population - in the reported use of Welsh at the next census (which was held in 2011), also an increase (not quantified) in the number of families using Welsh at home.

The document also brought into public circulation a number of key concepts through which the Assembly's vision of revitalization was to be understood. Iaith Pawb targets a social outcome that it repeatedly refers to as "a truly bilingual Wales" based on language "choice." It also specifies the aim of ensuring that the Welsh language is a "visible" resource for Welsh distinctiveness and national pride.

We want Wales to be a truly bilingual nation, by which we mean a country where people can choose to live their lives through the medium of either Welsh or English and where the presence of the two languages is a visible and audible source of pride and strength to us all. (Iaith Pawb, section 2.15) 
The phrase "visible and audible" implies a commitment to increasing public displays of Welsh, and "choos[ing]" a linguistic "medium," further implies paralleled displays of the two languages. As we see below, these principles have been upheld in generating the dominant patterns of "parallel texting" language display in contemporary Wales. ${ }^{4}$

The Assembly Government funds specialist services and advice for designing bilingual documents and texts of various genres, again showing that public displays of bilingualism fall squarely within current language-policy objectives (Coupland \& Bishop 2006; Coupland 2010a; cf. C. H. Williams 2008:ch. 8). The genres of public signage under the control of national and local government authorities - the ones that Kallen (2010) describes as falling within "the civic frame"-reflect legal requirements (following the 1993 Act). But language displays deriving from earlier political regimes are also still in evidence in Wales. Prerevitalization and predevolution ideologies were textually sedimented into Welsh public spaces-sometimes quite literally "set in stone"- before the 1960s, and a visible record of policydriven language-ideological shift is therefore available in public signage.

Governmental policy is of course not the only ideological source that shapes bilingual frame displays in Wales. It is generally recognized that political momentum towards revitalization was built up through activist initiatives (from the 1960s onwards), and language displays are still a campaigning resource for some activist groups (cf. Merriman \& Jones 2009, E. Williams 2009). A quite different set of priorities emerges from cultural tourism, and, as we will see, Welsh/English bilingualism can be visualized in ways that are more consistent with tourism consumption than with minority language politics. There are also more laconic and creative initiatives that stand outside all of the other institutionalized ideologies.

This is the wide range of social forces whose impact on language display in Wales I now want to identify by looking at a rather eclectic set of photographic examples. The study is synchronic in that the images analyzed are all currently on display, even though they emerge from different historical trajectories. The texts appear in different display genres, and they do not constitute a formal sample of any sort. I have not chosen the examples to represent any particular geographical regions or urban "scenes," as might be required in some traditions of LL research (cf. Ben-Rafael, Shohamy, \& Barni 2010), although I comment as necessary on some regional and geographical factors. As explained above, I am less interested in the areal or "landscape" placement of the displays, and more interested in the range of frames available for bilingual display and how they are ideologically and textually configured. The frames I discuss are as follows: (i) the frame of nonautonomous Welsh, (ii) the frame of parallel-text bilingualism, (iii) the frame of nationalist resistance, (iv) the frame of Welsh exoticism, and (v) the frame of laconic metacultural celebration.

THE FRAME OF NONA U T O OMOUS W E L H

The "organizational premises" (in Goffman's expression) for language display in Wales throughout most of the twentieth century were either that Welsh was 
inappropriate for use as a public code (so that public signs of most sorts in Wales were in English only) or that Welsh was in various ways reliant on English for its viability. These assumptions naturalized ways of displaying Welsh, when it was in evidence, as a nonautonomous code. This frame is now being vigorously supplanted (see below) in a process that developed momentum in the 1970s. By 1970 most areas of Wales had been heavily anglicized (C. H. Williams 1990), very thoroughly so along the eastern border with England, but not only there. The coastal cities in the southeast, including the capital city of Cardiff, had grown very rapidly during Industrialization and drawn in migrants from Wales but also from further afield, especially from Ireland, Liverpool, and the southwest of England. Around 1970 they had very few Welsh speakers, although, like all of Wales, they had a rich cultural inheritance from the Welsh language, most visibly in place names. Older street names in Cardiff, like those in Figure 1, are therefore a good example of residual public entextualization in the first frame, where Welsh was in various ways delegitimized and publicly subordinated to English.

The six images in Fig. 1 name four different Cardiff streets. The signs share the characteristic of embedding names that are in some sense Welsh within an English matrix - the head noun in each phrasal name has the English word Street or Road. Already, then, we see an overt grammatical dependence relationship, but also, arguably, an implied cultural dependence. The city districts in question were constructed between 1910 and 1940, and when the streets were first named, existing Welsh place names - including names from the nonurban hinterland (Treorkey/ Treorky and Llantrissant are both villages outside the city) or other Welsh words - were commonly incorporated into an English-dominant naming system.

This frame is also cued in the orthographic representation of Welsh words in the Fig. 1 examples. Orthographic norms for Welsh were first published in 1928
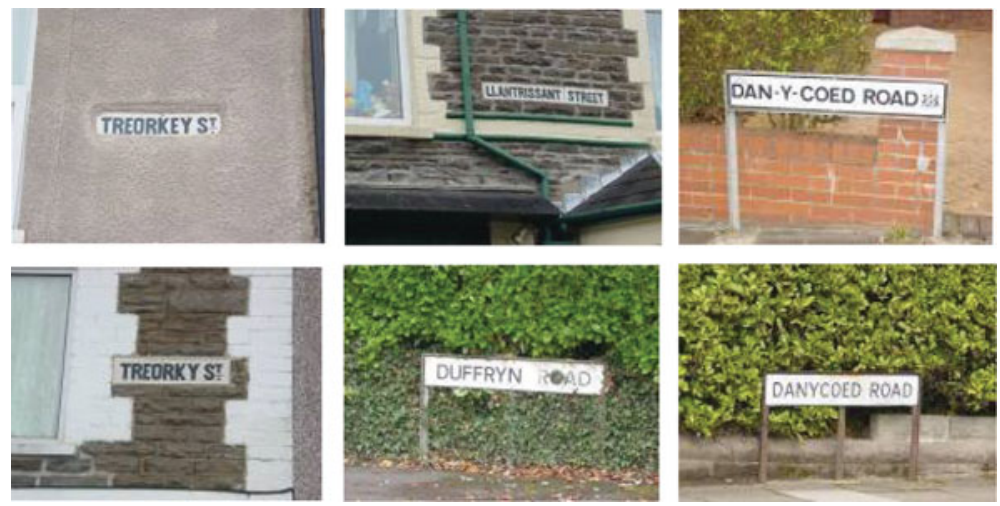

FIGURE 1. Street-name signs in Cardiff. 
(Morris-Jones 1928); see discussion in Harley (1971) and Moore (1986) and placename listings in Owen (1998). This generally explains the coexistence of different spellings of Treorkey/Treorky and Dan-Y-Coed/Danycoed in Fig. 1, also the presence/absence of hyphens marking morpheme boundaries in Danycoed/Dan- $Y$ Coed 'Under the wood'; the streets were first named before Welsh orthography was standardized. But the displayed versions (in these and very many other instances) clearly show a leaning towards English orthographic principles when there was doubt or dispute over how Welsh item should be displayed. So, doubled $<\mathrm{s}>$ in Llantrissant respected an English spelling rule (the middle syllable is stressed and pronounced with short / a /), when single $<s>$ would have respected the morphological structure of the name in Welsh - llan 'church' [of the] tri 'three' sant 'saints.' Similarly, $<\mathbf{u}>$ in Duffryn 'Valley,' in place of now normative Welsh $<y>$, followed an English letter-sound correspondence rule, not a Welsh one (even though it respects the Welsh rule that realizes phonological/f/ as $<\mathrm{ff}>$ ). Spellings of Treorkey/Treorky, a former mining village in the Rhondda Valley, with $<\mathrm{k}>$ and $<\mathrm{y}>$ reflect English spelling norms used to render pronunciations that, in 1910, were already anglicized versions of a Welsh place name, morphologically constructed from tre 'village' or 'town' and gorchwy 'a stream that defines a boundary. ${ }^{5}$

In the first frame, public displays of Welsh are scaffolded by English in ways that are considered illegitimate and inauthentic today. Even in the few examples considered, we can see that early twentieth-century displays of bilingualism in Wales saw no difficulty in blending Welsh and English, even if (to invoke a more contemporary revitalization discourse) the blending process subjected Welsh to the normative requirements of English, not vice versa. This, after all, was one way to interpret anglicization (C. H. Williams 1990), which in Wales has referred to more than a statistical pattern of demographic shift away from Welsh language use. Anglicization also took the form of linguistic syncretism (Urciuoli 1995), Welsh and English "growing together," and in many cases English "growing around" or circumscribing Welsh.

\section{THE FRAME OF PARALLEL-TEXT B IL IN G U A L IS M}

The current revitalization of Welsh builds on the ideological premise that Welsh is not only a fully autonomous code but a code that focuses national identity for all Welsh people. This stance, at least, is a cornerstone of the devolved Assembly's revitalization policy for Welsh. As we saw earlier, inclusive national ownership of Welsh is flagged in the title of the planning document Iaith Pawb 'Everone's Language' which envisages Welsh people exercising "choice" between the use of Welsh and English within a "truly bilingual Wales." These concepts have been critically explored elsewhere (Coupland \& Bishop 2006, Musk 2010), but they find direct expression in a particular pattern of language display. The dominant pattern of institutionally driven bilingual display in contemporary Wales, certainly 
over the last two decades, projects Welsh and English as (textually) parallel and (evaluatively) equivalent autonomous codes. Figures 2 and 3 show several instances.

Linguistic elements in each of the four images in Fig. 2 have directly equivalent referential meanings in Welsh and English (but see the later discussion of the "Englishness" of Carmarthen), with the left-side images vertically prioritizing Welsh over English and the right-side images prioritizing English over Welsh. This at least follows Kress \& van Leeuwen (2001), who comment on the meanings of different patterns of text layout (see also Reh's (2004) category of "duplicating multilingual writing"). Several other design principles govern these bilingual displays. As well as their referential equivalence, code elements are given equal visual
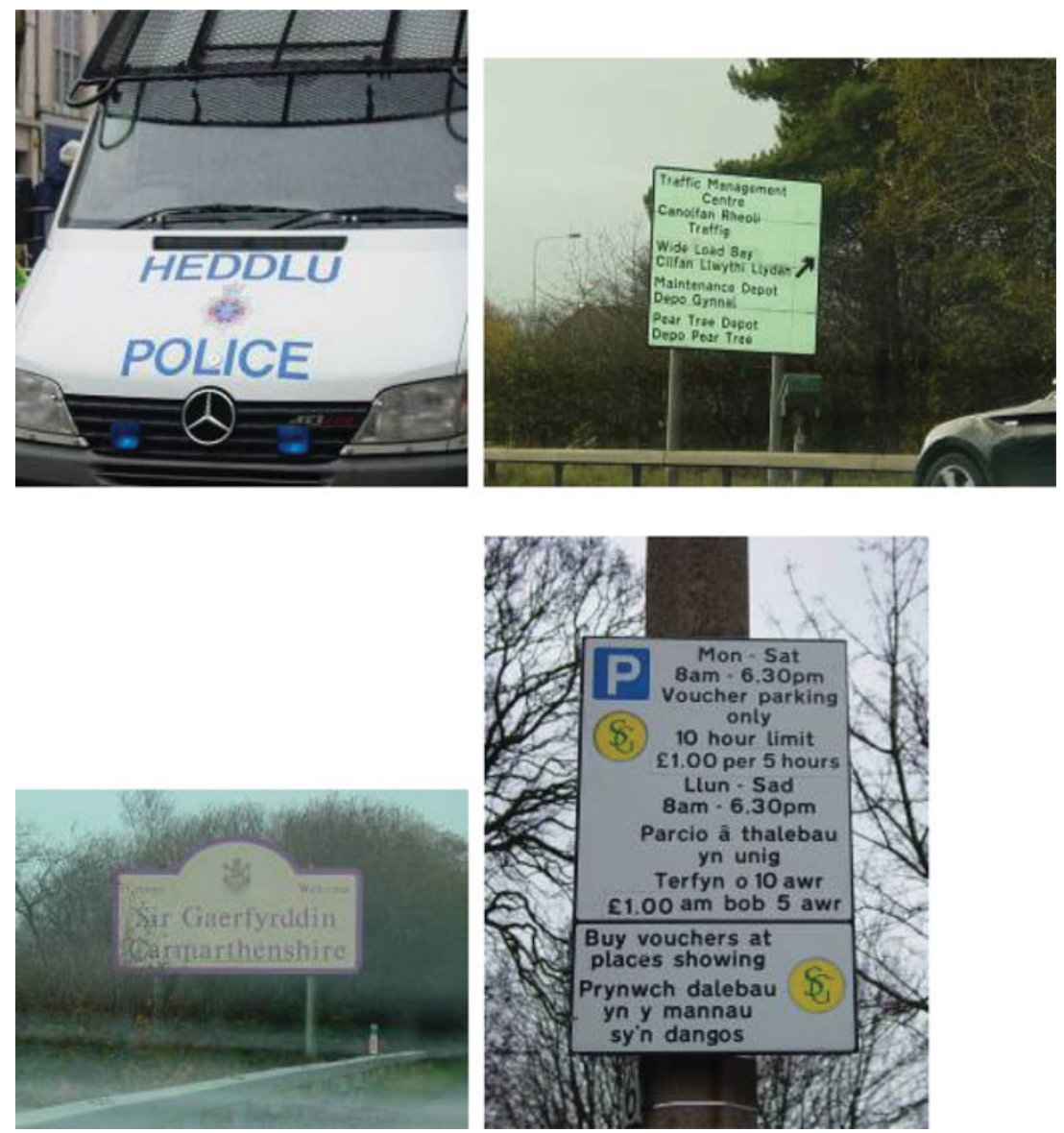

FIGURE 2. Parallel-text signage in Wales. 
prominence in size and typeface (although HEDDLU, the Welsh word for POLICE, displayed on the police patrol vehicle, is slightly shrunk to fit the same amount of space as its English equivalent). Code integrity is respected, to the extent that Pear Tree Depot is rendered in Welsh as Depo Pear Tree, marking different orthographic versions of the French loanword in English and Welsh, but maintaining Pear Tree (and its English noun-phrase syntax) as a commercial title in both versions. The parking restriction sign again displays its content in two paralleled languages, despite the fact that most of its information is numerical. Both English and Welsh text used $\mathrm{am}$ and $\mathrm{pm}$, presumably because these expressions are analyzable as sourced from Latin, although some recent Welsh signs substitute $\langle y b\rangle$ and $<\mathrm{yp}\rangle$ for $\langle\mathrm{am}\rangle$ and $\langle\mathrm{pm}\rangle$, as newly coined abbreviations of the Welsh phrases $y$ bore 'in the morning' and $y$ prynhawn 'in the afternoon.'

The principle of equality is not fully sustained, however, because a politics of code sequence is visible in the images. Fig. 2 shows how the southwestern county of $\mathrm{Sir}$ Gaerfyrddin/Carmarthenshire (where there is a relatively high density of bilingual speakers) has opted for Welsh-first signage, with Welsh text to the left of or above English text. (In fact this roadside sign marks a language-display "isogloss," announcing the county boundary for travellers moving west along the M4 motorway corridor in south Wales, which coincides with a shift from English-first to Welsh-first civic bilingual displays.) The national police service has opted to display Welsh first, perhaps partly because its logo-ized vehicles move between more and less English-dominant zones. The right-hand signs in Fig. 2 are both located in southeast Wales (with much lower densities of bilingual speakers).

In Fig. 3 the Cardiff University logo normatively has English above Welsh, although the university has given dispensation to its School of Welsh (signed in the lower left image as $Y$ Gymraeg/Welsh) to display Welsh first. The right-hand images in Fig. 3 show how signage materially embedded in the concrete and tiled structures of Cardiff Central (railway) Station were originally in English only, and have now been either overwritten (in the case of the public name of Cardiff's main railway station, inscribed in the façade of the building) or supplemented (in the case of its internal platform notices inside the station) by Welsh-first parallel text. ${ }^{6}$

The frame of parallel-text bilingualism articulates what Heller has called the ideology of double monolingualism:

while bilingualism is valued, it is only valued as long as it takes the shape of "double monolingualism." One is expected to speak each "language" as though it were a homogeneous monolingual variety... Mixed varieties, which of course are common in bilingual settings, are frowned upon. (Heller 2002:48; see also Heller 2003)

Parallel-text displays in Wales iconize current language policy-a visible consequence of status planning (Cooper 1989). But display and policy both need to be understood historically, and interpreted as moves to supplant the 


\section{CARDIFF UNIVERSITY \\ PRIFYSGOL CAERDY}
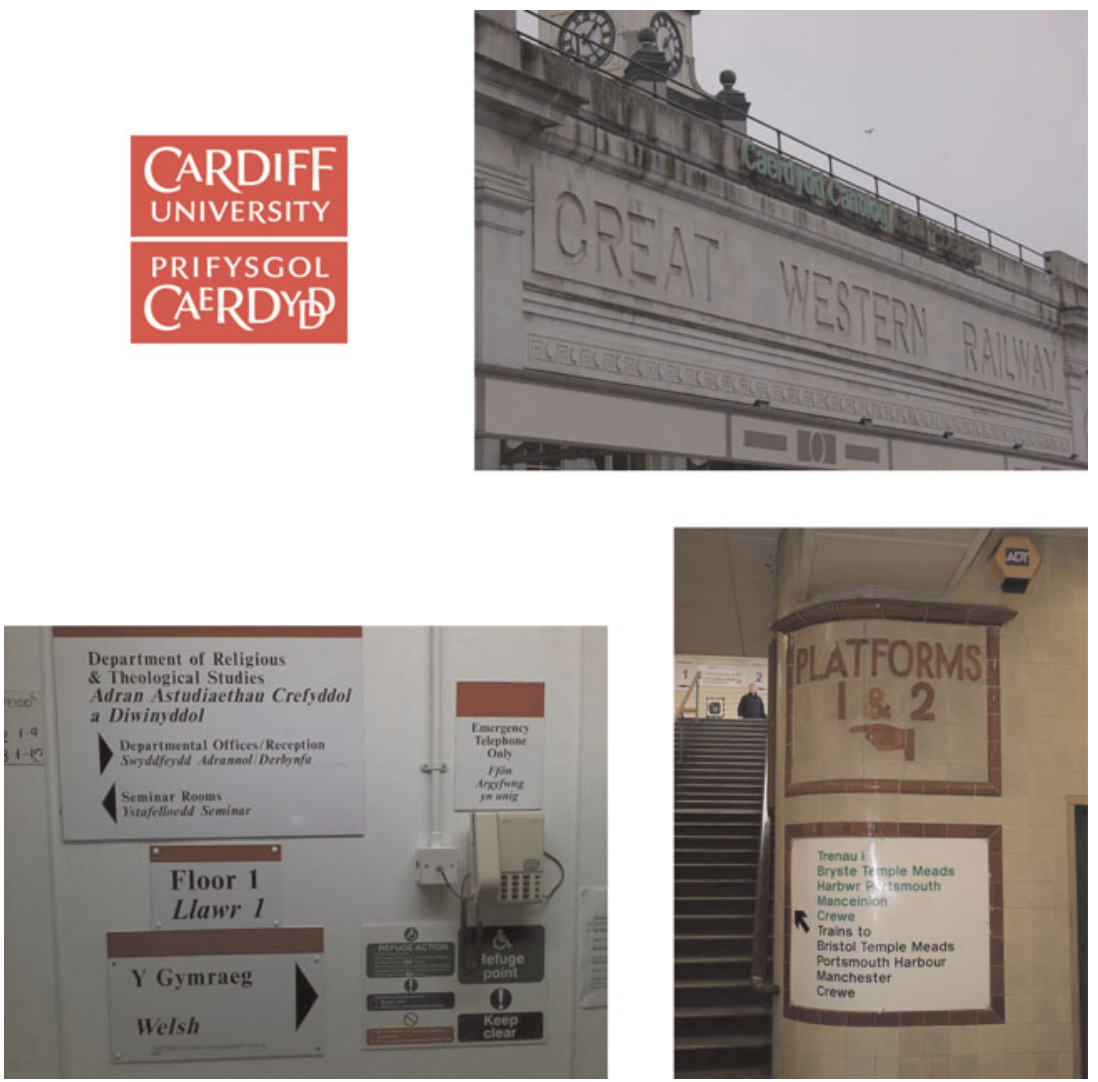

FIGURE 3. Code-priority and over-writing.

earlier ideology of nonautonomous Welsh. We know from informal accounts by language planners in Wales that they feel that this shift, away from a pernicious syncretism favoring English, is emancipatory. Parallel texting in Wales probably has some way further to run. We are, for example, beginning to see some street names in Cardiff, similar to those in Fig. 1, recoded into double-named forms. ${ }^{7}$

As Heller argues, however, the ideology of double monolingualism is also potentially hegemonic. It gives textual form to a standard language ideology that challenges linguistic syncretism, when the character of Welsh-English bilingualism, as it has evolved over centuries, is quite generally syncretic. Place names again provide the clearest and most pervasive instances. A majority of Wales's town and city names are Welsh-derived, and anglicized versions of Welsh names settled into public use, as with Carmarthen (in Fig. 2). The (re)standardized Welsh form Caerfyrddin has Caer, from Latin castra meaning 'fort,' and a 
mutated form of Myrddin, a Welsh equivalent for Merlin (the mythical magician, although this etymology is disputed; see Owen 1998:22). The form Carmarthen is nowadays treated as "English", although it is a hybridized syncretic form. The name Caerfyrddin has been available for long enough to have become socially embedded in many Welsh speakers' usage, though not as thoroughly as Carmarthen. But many Welsh-language place names (several others are discussed in Coupland 2010a) that are currently being coined lack this degree of embedding, within explicitly labelled "language standardization" activities. ${ }^{8}$ In those cases there is a risk of undermining socially experienced and spatially embedded authenticity in the authoritative quest for linguistic authenticity.

The first two frames represent the main axis along which civic control of visible bilingualism in Wales has been exercised. Monolingual English signage (not represented in the photographic data) displays a version of the first ideological frame, and many commercial organizations, not currently subject to the 1993 Act, still treat Welsh as inappropriate or irrelevant to their public image. This is likely to change under governmental proposals currently being debated (see n. 4). In contrast, texts motivated in the three remaining frames are far less frequent, and they are much less normative. But these other frames represent important parts of the language-ideological mix in contemporary Wales, each of them projecting its own metacultural values.

\section{THE FRAME OF NATIONALIST RESISTANCE}

Occasional public displays "shout out" demands about linguistic ownership, entitlement, and obligation, continuing the tradition of language activism in Wales. Figure 4 has two images, each linked to the language and housing pressure group Cymuned 'Community.' ${ }^{9}$ The group self-identifies in the second image (where cyfiawnder means 'justice'), which has appeared as a billboard poster in several north Wales locations and is also used an online campaigning document. ${ }^{10}$ The first image ${ }^{11}$ shows a caravan sited near a busy road close to Caernarfon in the county of Gwynedd in northwest Wales. Gwynedd has the highest densities of Welsh-language usage in Wales and is associated with particularly high levels of ethnonationalist identification (Coupland, Bishop, Williams, Evans, \& Garrett 2005). The caravan is used by Cymuned to publicize their "anticolonization" (anti-in-migration) and pro-Welsh language rights campaign. The displayed text includes TAI I BOBL LEOL! 'HOUSES FOR LOCAL PEOPLE!' and ARDAL GYMRAEG 'WELSH AREA.'

The ideological assumptions of the nationalist resistance texts are very different from those of Iaith Pawb. In the caravan display the demand carried through the imperative SPEAK posits an implied noninclusive "we," the group that owns and lays claim to rights over Welsh (OUR LANGUAGE), which "you," the idealized addressee group, do not speak and have no rights to. An alternative interpretation is conceivable, where "our" might be inclusive, along the lines of Iaith Pawb's 

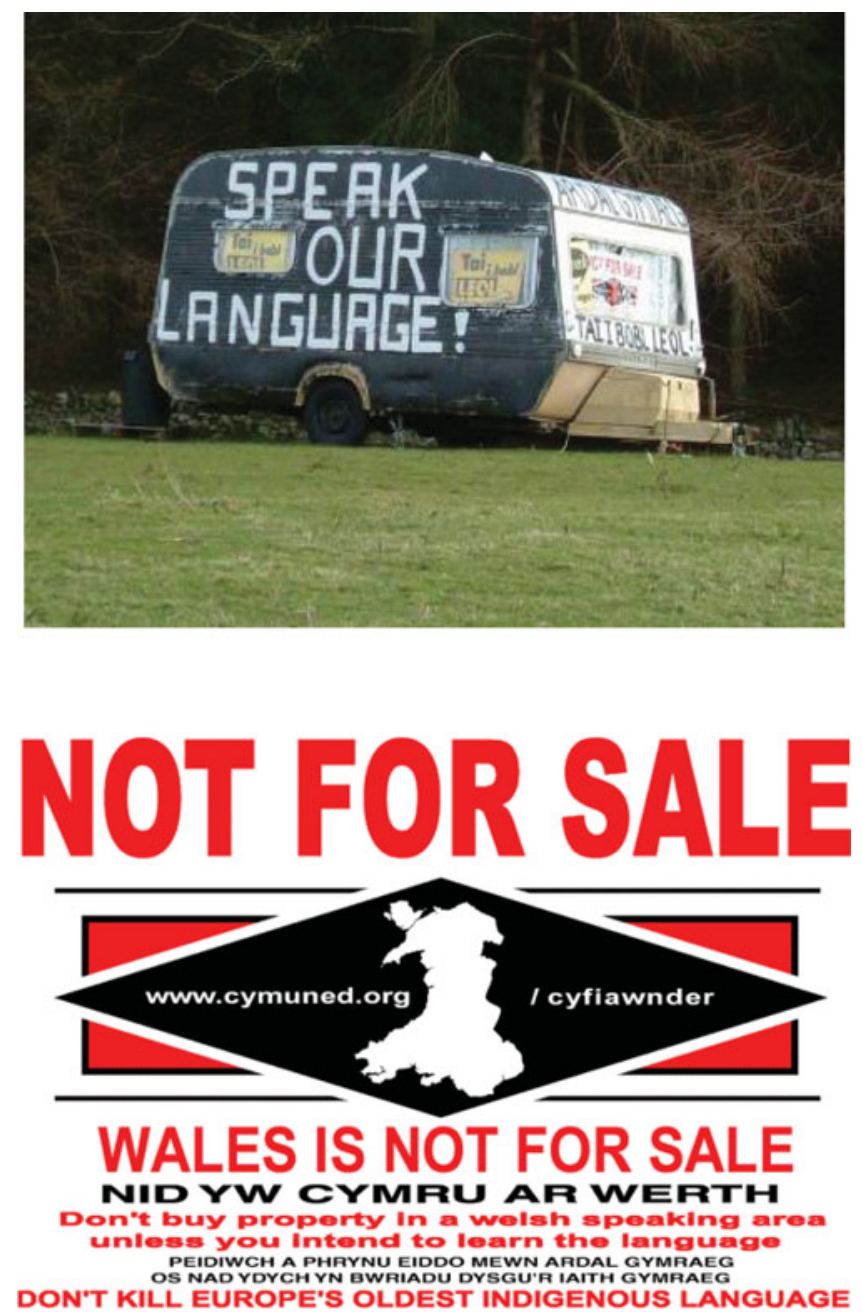

FIGURE 4. Nationalist resistance.

assertion that Welsh is "everyone's language"; that is, "you Welsh people who do not speak Welsh, should speak our shared language." But the caravan texts are on display in Gwynedd, with a strong and continuous history of ingroup/outgroup disputes around the ownership and use of Welsh. In Gwynedd "local people" (the pobl leol referenced in the text, along with their territorial base, ARDAL GYMRAEG), at least in Cymuned's discourse, are the Welsh-speaking local ingroup, under threat from "incomers" who, it protests, do not learn Welsh in sufficient numbers. People moving to settle in north Wales are predominantly from the northwest of 
England, often older people retiring in coastal or rural areas. These "incomers" are very probably the group identified by you in the second text, the campaigning poster. The roadside caravan text "shouts out" to drivers, who might include those "coming in" to the Welsh "heartland."

The injunctions Don't buy... and DON'T KILL... in the second image insistently forge an ideological link between the commodification of culture and what Skutnabb-Kangas \& Phillipson (2010) describe as the potential of English to commit "linguistic genocide" over minority languages. Cymuned ideologizes Welsh not simply as being equivalent to English but as the indigenous, ancient, and rooted language of Welsh-speaking Wales. It defines a cultural space (ARDAL GYMRAEG) which, despite the map in the second image, is not assumed to be all of Wales, but the rural Wales "heartland" zones. So this is an example of Heller's "traditionalist discourse," which she says "was based [in French Canada] on the importance of resisting English domination by remaining homogeneous... and faithful to values which were (and still are) understood as traditional, in the sense of linking contemporary actors and practices with a legitimizing past" (Heller 2002:49-50).

Texts in the nationalist resistance frame have a distinctive key, indexed by their style of interpersonal address and their on-record pragmatics. Like the civic frames (frames 1 and 2) they are "serious," but the third frame's texts are also threatening and impositional, as opposed to just being bureaucratically normalizing. Their authority is constructed as moral, not institutional. In the caravan instance the texts are hand-produced and vernacular, implying personal investment. Their use of Welsh and English, despite elements of parallelism in the second image of Fig. 4, is also distinctive. The contemporary-mode bilingual civic texts (in the second frame) suggest that their institutions favor nuanced linguistic equality, addressing readers in their "language of choice." But Cymuned needs to address its ideal outgroup readers (who it presumes are non-Welsh-speaking) in English, echoing the longstanding and, for some, painful irony that a good deal of Welsh language politics and policy-making has needed to be transacted through English. By the group's own logic of intergroup relations, it would be counterproductive for Cymuned to voice its strongest demands only in Welsh. So Welsh functions ethnosymbolically (in Eastman and Stein's sense) in texts of this sort; it is there to evidence the cultural resources that are at stake.

\section{THE FRAME OF WELSH EXOTICISM}

In a starkly contrasting fourth frame, Welsh again appears as an ethnosymbol, but this time as an ephemeral and consumable cultural curiosity rather than as a deeply rooted national resource.

Versions of the Fig. 5 image appear frequently in online tourism promotions and tourist postcards (cf. Jaworski 2010), therefore as secondary, mediated versions of Welsh linguistic landscapes. ${ }^{12}$ The image is of a railway station sign at a small 


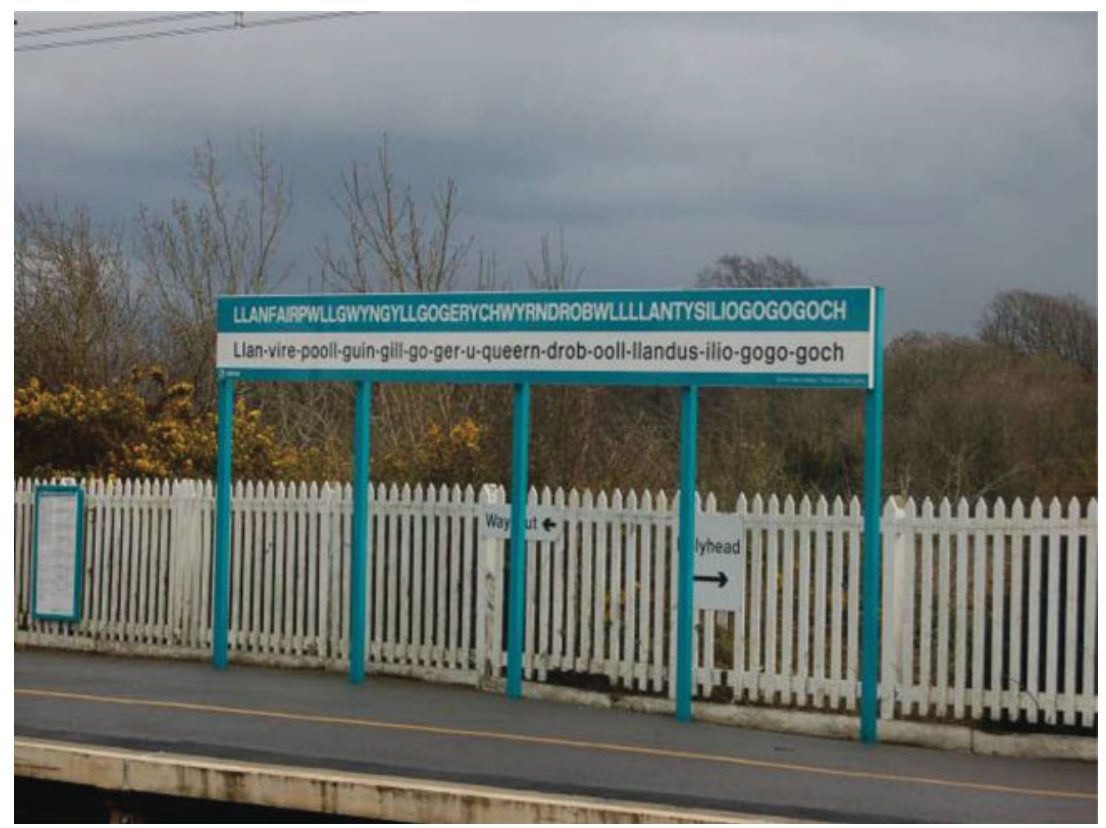

FIGURE 5. Exoticizing Welsh.

town, Llanfairpwllgwyngychgogerychwyrndrobwllllantysiliogogogoch, in Ynys Môn/Anglesey in north Wales. The name, conventionally abbreviated to LlanfairPG or Llanfairpwll, semantically denotes a series of physical and natural features ('The church of the fair of the white pool...') and tourists are sometimes encouraged to visit the town and make their own assessment of whether these features actually exist in the locality. In the present image the railway station sign gives a rough, syllable-by-syllable guide to how the name is pronounced, using English orthographic conventions to approximate Welsh phonology. Note how the placename display contrasts semiotically with the small, instrumental, English-language direction signs indicating Way out (of the station) and Holyhead (the line's destination).

The organizational premise here is that this Welsh place name is communicatively exotic-impossibly long and unpronounceable without assistance. It is a language display designed to amuse and to puzzle, whatever its more conventional place-naming function. Thurlow \& Jaworski (2010:143) point out that identifying local languages to be "problematic" is as much of a tourist trope as identifying local languages to be "unproblematic." But with LlanfairPG there is more scope for exoticizing in the "problematic" direction, because claiming superlatives ("the longest place-name in Wales") is itself a tourism trope. In the frame of Welsh exoticism the 
metacultural value of Welsh lies in its interesting and amusing "difference." Although the key of this frame could be called playful, Thurlow and Jaworski go on to argue that representations of this sort also erase cultural value. The fact that the LlanfairPG sign is geographically sited in Gwynedd, not so far from the Cymuned caravan display, highlights the conflictual potential of ideological frames. What one group (e.g. of tourists) might experience as a linguistic curiosity, others (e.g. activist local Welsh speakers) might experience as cultural derision.

Texts exoticizing Welsh sometimes occupy influential spaces. The Wales Tourist Board's website, VisitWales, has in the recent past ${ }^{13}$ used the following opening sequence:

Sut mae, croeso i Gymru.

Hello, welcome to Wales.

That's right, not Dutch. Not Latin. It's Welsh.

The second line of this text, in English, parallels the first. The third line retrospectively objectifies the first line, anticipating how readers will be reacting to the Welsh greeting. Visit Wales's promotional idea here is presumably that the Welsh language will draw in tourists, captivated by its appealing but nonthreatening inaccessibility. The sequence also constructs Welsh as a commodified cultural object with several disqualifying social attributes. As with the LlanfairPG sign, the implication is that Welsh is impenetrable (NOT DuTCH, implying "although you might have thought it was 'double Dutch'—a familiar phrase implying incomprehensible language — and it needs captioning") and lacks vitality or practical utility as a language (NoT LATIN, implying "although you might have thought it was a 'dead language""). The currently more prominent VisitWales account of the Welsh language is again exoticizing, and includes the following sequence: ${ }^{14}$

It's called Cymraeg in Welsh, and it's a language with entirely regular and phonetic spelling. Although you wouldn't necessarily know it to look at a word like Llanfairpwllgwyngyllgogerychwyrndrobwllllantysiliogogogoch.

Even though Welsh having "regular and phonetic spelling" might appear to de-exoticize it, the rhetorical point is that such regularity in fact won't help readers to cope with LlanfairPG.

THE FRAME OF LACONIC METACULTURAL

C E LE B R A T I O N

I have struggled to find a title for the fifth frame, and the texts I want to consider are certainly idiosyncratic. But they provide a valuable counterpoint to texts in the previous four frames, while also reminding us that language display can be a personalized and personalizing practice. The examples in Figure 6 are of metacultural Tshirt displays (cf. Johnstone 2009), and particularly a range of designs produced by a small north Wales company, cowbois. ${ }^{15}$ 

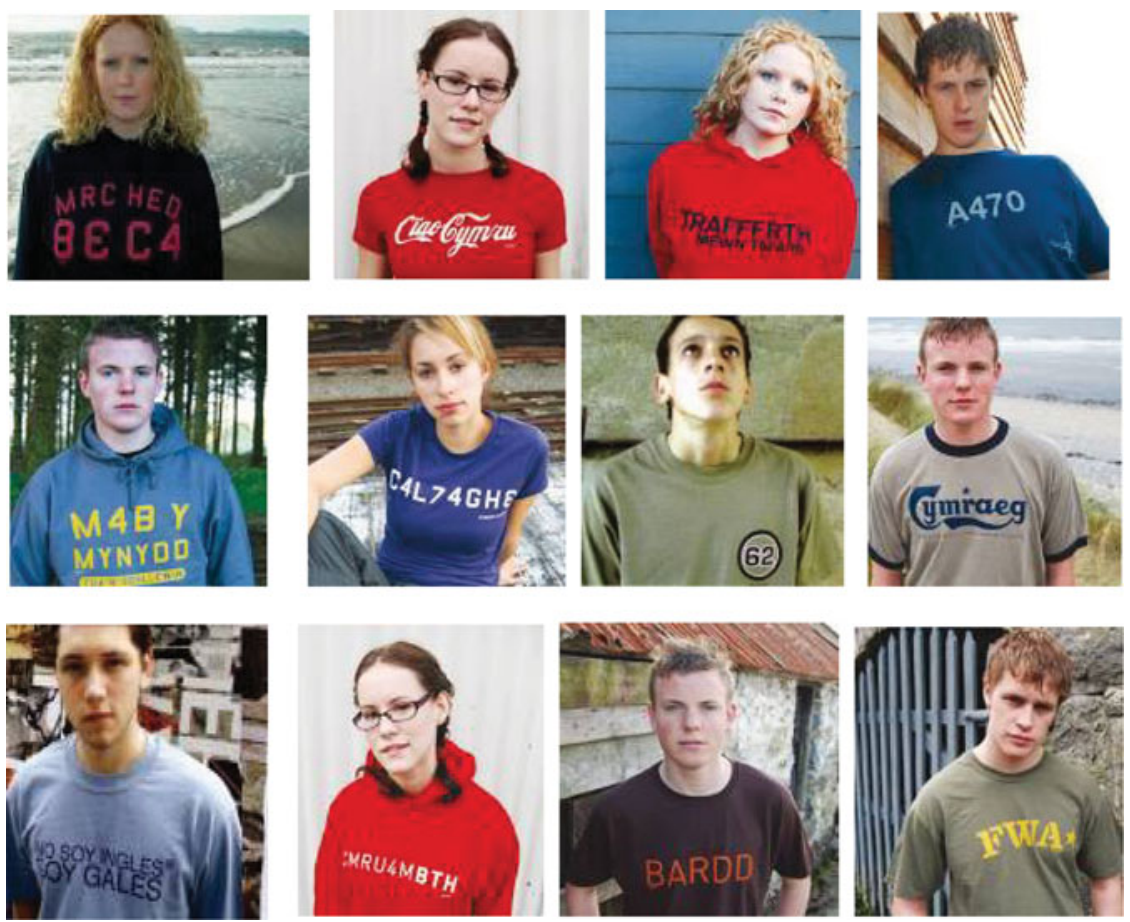

FIGURE 6. Metacultural T-shirts (with acknowledgement to cowbois.com).

The name cowbois is a transliteration of English cowboys and knowingly transfers the ethos of cultural naivety often associated with use of the English term in the film and TV history of the American "wild west." When the cowboy concept has surfaced in Welsh media contexts - for example, in the Welsh-language television comedy series Cowbois ac Injans or the English-language film Dogfood Dan and the Carmarthen Cowboy - it has been framed metaparodically, implying the supposedly unsophisticated culture of rural Wales - a wild west of its own. Metaparody (Coupland 2001) is a multiply voiced reference that incorporates parodying one's own role as a parodist, and the concept is generally applicable to the metacultural framing of cowbois' T-shirt texts.

The texts in Fig. 6 involve polylingual bricolage (cf. Dray 2010). Across the twelve instances, the matrix languages are variously Welsh, Spanish, Italian, and English. ${ }^{16}$ Some designs have no linguistic matrix: two are number-based and one is a proper name (a version of Calzaghe). The cowbois texts thematize language, or language-in-Wales, in different ways from different stances. In terms of address, some cowbois texts "speak outwards" from Wales to other language groups (NO SOY INGLES SOY GALES (Spanish), meaning 'I'M NOT 
ENGLISH I'M WELSH') and others "speak inwards" from other language groups to Wales (Italian Ciao, Welsh Cymru, 'Hello Wales'). The Cymraeg text might appear to be "Welsh only" (it means 'Welsh') but the cursive lettering provides an intertextual reference to the name of a global brand of lager, Carlsberg. English subscript (not readable in the photograph), Probably the oldest living language in Europe, parodies the well-known Carling advertising slogan, rekeying a familiar authenticity claim for the historic value of Welsh by styling it as a beer commercial.

A regular design principle is to fracture the linguistic scripting of Welsh, omitting letters or replacing alphabetic letters with numbers. Full forms of the texts in Fig. 6 would have been MERCHED BECA 'REBECCA'S DAUGHTERS,' MAB $Y$ MYNYDD 'SON OF THE MOUNTAIN,' and CYMRU AM BYTH 'WALES FOR EVER,' and similarly with CALZAGHE, the name of "Britain's only undefeated boxing world champion" (Joe Calzaghe, who has a Welsh and Sardinian family background). Fractured displays of Welsh deviate from the standard language ideology's requirement that Welsh should appear fully autonomous. For cowbois, Welsh does not need to be "complete" and "intact." The T-shirt display genre is of course not subject to institutionalized normative constraints, but it is unusual to see any public display of Welsh that is unsanitized and creatively manipulated.

Fracturing Welsh could be considered an exoticizing strategy, as in the fourth frame (above), but there, "real Welsh" is displayed and subverted, while in this fifth frame, fractured Welsh is rendered mysterious. There is a comparable economic context around the fourth and fifth frames, with Welsh-language text being commodified for different markets. T-shirt texts commodify language, and linguistic text can significantly increase the commercial value of a plain T-shirt (cf. Johnstone 2009). But the cowbois texts presume that consumers will want to share in the mystificatory celebration of Welsh language and culture, while the tourist texts presume that consumers will not want to engage. cowbois shirts do not focus or enregister a particular linguistic variety, as Johnstone's Pittsburguese shirts do. They play suggestively but inconclusively with Welsh cultural signifiers.

Their stance might be described as laconic, if the framing suggests (as it does to me) a noninsistent orientation and a laidback tolerance of incomplete meaning making. cowbois are happy not to foreclose on Wales and Welsh. They leave readers to puzzle over and perhaps to resolve their oblique cultural references (see Kallen \& Ní Dhonnacha (2010:27) for a discussion of comparable "linguistic anomalies" in some instances of Irish and Japanese commercial signage). But all of these references, once we understand them, are celebratory. "Rebecca's daughters" refers to a historical moment of organized rebellion, by men dressed as women, against English-imposed tollgate charges; Cymru am byth is a common ethnonationalist exhortation; Joe Calzaghe is a winning Welsh sportsman, and so on. So the frame by no means implies an absence of national alignment.

One of the "straightest" cowbois Welsh inscriptions might appear to be TRAFFERTH MEWN TAFARN 'TROUBLE IN THE TAVERN,' unless readers 
recognize the literary allusion to Dafydd ap Gwilym's revered, bawdy fourteenth century poem. Other texts also make veiled reference to deeply coded Welsh historical and cultural phenomena and events, and again they are often re-keyed in the T-shirt displays. In the Fig. 6 examples, FWA refers (via English initials) to the Free Wales Army, a small-scale paramilitary nationalist organization of the 1960s that led a campaign of violent action against English cultural incursions (to see it from Cymuned's general standpoint). But the visual styling of the shirt and the added star recontextualize and ironize this historical reference. The star possibly hints at an American army uniform, and when this is a T-shirt theme, it is as likely to imply pacifist as militarist sympathies. 62 is a veiled reference to a key year, 1962, for the revitalisation of Welsh, which saw the formation of Cymdeithas Yr Iaith Gymraeg, the Welsh Language Society, and the Saunders Lewis's seminal lecture, Tynged yr Iaith ('the Fate of the Language'), which was held to signal the birth of Welsh nationalism. But for those who make these historical connections, there is once again no clear indication of a political stance towards these events. $A 470$ is the designation of the only major road (an "A-road") linking north and south Wales, and the road is widely said to be inadequate. The shirt text therefore hints at experiences of cultural division within Wales and the "remoteness" of the "heartland" north (cf. the earlier reference to "son of the mountain" and the general "wild west" allusion in the cowbois name). BARDD means 'bard,' a poet successful at the national eisteddfod, a ritualistic celebration of traditional Welsh performance culture, but with some crucial dissonances around age and stance in this particular display. Can bards be youthful, as the wearer of the shirt is in the image? And for that matter, do bards wear T-shirts, let alone shirts declaring "I'm a bard"?

\section{I S C U S S I O N}

A frame analysis perspective allows us to see how language display can articulate different language-ideological stances and contests between stances. In the data we have seen some old minority language antagonisms being played out, with, in this case, the linguistic autonomy of Welsh at their center. Perceived English hegemony over Welsh, and therefore ideologies of anglicization and anti-anglicization, underlie the first and second frames. Texts in the first frame, the frame of nonautonomous Welsh, still visible in the environment but seen from a contemporary standpoint, iconize that historical hegemony. Those in the second, institutionally dominant frame, the frame of parallel-text bilingualism, assert the equality of Welsh and English. They therefore credentialize Welsh as a viable national code alongside English, promoting an ideological parallelism that articulates the main planning discourse of a "truly bilingual Wales."

The parallel-text ideology is not without its limitations. (Re)inventing Welsh place names and inscribing them ethnosymbolically in language displays are vibrant metacultural activities in contemporary Wales. They make the public face 
of Wales "more bilingual." But with place names, there is some risk of dehistoricizing Welsh place designations, which, through syncretic development, have come to symbolize a more complex and less clear-cut relationship between languages. The syncretic process underlying the first frame was one-sided and it devalued Welsh, but syncretism is the normal condition of codes in contact. In the parallel-text frame, Welsh on display has to be fully autonomous, thoroughly standardized, pulling back from syncretic and hybrid development. Yet it may prove to be counterproductive to invest too heavily in standardizing and partitioning the Welsh language, when revitalization is likely to require an open ideological stance and a more pragmatic version of "bilingual Wales."

Language activism has already to some extent influenced planners' vision of a "truly bilingual Wales," but activists are likely to feel that a free-market consumers' "choice" of either English or Welsh (as set out in Iaith Pawb) fails to address current threats to the vitality of Welsh. Their ways of representing Welsh in the third frame, the frame of nationalist resistance, prioritize the "heartland" Welsh-speaking areas, particularly in northwest Wales. Arguments about the naturalness of linguistic syncretism are likely to go unheard in that frame. But the Welsh Assembly Government, representing an all-Wales electorate and recognizing the legal, cultural, and financial implications of strongly protectionist policies, cannot fully accommodate activists' traditionalist discourse.

The timescale of Welsh revitalization is an important consideration behind these framed displays. In Wales there is now an opportunity to work up a bilingual Wales, in one conception or another, as a serious national project. But this opportunity has come round in the context of global changes, which make it particularly difficult to sustain traditionalist or nationalist discourses in public policy, or even in local communities, and when, despite the global financial instability of recent years, cultural globalization is running ahead rapidly (Coupland 2010b). As part of this, it is becoming harder to hold on to traditional accounts of language boundaries, language ownership, and language rights. Texts in the fourth, tourism-focused frame, the frame of Welsh exoticism, display Welsh as a cultural commodity with more ephemeral values. Visit Wales's slogans are an awkward effort to reconcile the supposedly authentic values that Welsh has as "Europe's oldest living language" with the interests of mobile and diverse tourist groups.

All acts of linguistic display commodify languages (Leeman \& Modan 2009), but the fourth frame also disembeds Welsh from its lived history and is in danger of bypassing its cultural value altogether. In other research (e.g. Coupland, Bishop, Evans, \& Garrett 2006), we have found a tendency for people in Wales to express stronger support for using Welsh in "ceremonial" contexts, such as singing the Welsh national anthem or choosing Welsh names for children, than for use of Welsh in workplaces and in home settings (which are the domains explicitly prioritized by revitalization agencies). There is an important difference between ceremonializing and exoticizing a minority language. The first implies respectful if qualified recognition and the second implies short-term consumerism. 
Where they overlap is in the assumption that a language can be valued outside of its core communicative function. Language planning in Wales is seriously investing in promoting Welsh in the core domains of home and work, but it is likely to prove far harder to "grow" the Welsh language (to use a planner's metaphor) in those domains than in language-display conventions.

I have emphasized the metacultural function of language display, and each of the five frames proposes a different version of Wales's linguistic culture. However, each of the first four frames in its own way suggests that it is LANGUAGES that matter most, in themselves as codes, and not the cultural distinctiveness that bilingualism might facilitate. In the first frame, what matters is for English to contain Welsh. In the second, a standard Welsh must match a standard English. In the third, Welsh is all that matters in the heartland zones. In the fourth, Welsh matters very little, but consuming it might be entertaining. In contrast, the cowbois texts show up the limits and perhaps the uncoolness of form-focused bilingualism. In what I have called the frame of laconic metacultural celebration, the cowbois texts tantalize consumers with ironic references to cultural richness that lies beyond linguistic form in an ideologically open and flexible bilingual and multilingual culture. cowbois celebrate incompleteness of linguistic form and hybridity. They allow languages other than Welsh and English into public spaces, and in doing so they remind us that Wales has tended to limit its conception of multilingualism to the politics of Welsh and English, when other languages and groups raise their own concerns (C. Williams, Evans, \& O'Leary 2003).

cowbois is of course a commercial company, selling its shirts, and the idea of Wales, nationally and globally via the Internet. But they manage to occupy this niche without taking an overly reductive stance on the cultural value of Wales and Welsh. They project a youthful confidence in the vitality of multilingual Wales, because, in their own ideological premises, Welsh does not need to be linguistically sanitized as a code or culturally contained within a protective "heartland." Their texts playfully but thoughtfully dwell on what might continue to distinguish Wales culturally, nonlinguistically as well as linguistically, but without positioning the Welsh language as the sole cultural commodity that is at stake. They invite a metacultural discourse about how contemporary Wales might orient to its older literary and political myths, but also to its more immediately salient everyday concerns. Is Trafferth Mewn Tafarn a reference to a treasure of old Welsh literature or to contemporary youth drinking culture? Can some sorts of bardic creativity be sustained outside of the old ceremonies? Is it nowadays cool to be a "son of the mountain," at what has been considered "the wrong end of the A470"? Can and should some version of Welsh political resistance survive in the global world of military conflict?

Bauman \& Briggs (1990) argued that it would be a mistake to underestimate the transformative potential of metacultural performance, and language display is a distinctive resource for performing a culture. This study suggests, however, that language displays can be ideologically configured DIFFERENTLY, to perform significantly DIFFERENT versions of a bilingual culture, concurrently. Governments and 
their agencies have had the institutional means to imprint their own current language-ideological visions on public spaces, but they are not the only agents in the process, and their framings are not necessarily definitive. One shift among the many that are taken to constitute globalization is a freeing up of resources and technologies that allow individuals and groups other than governments to display their own cultural visions in public, in their own frames. It may be that smaller players (exemplified by Cymuned and cowbois in this study), OUTSIDE the familiar centres of linguistic authority (such as language planning departments designing and implementing legislative frameworks), will become more influential (Pietikäinen 2010). In any event, language displays are likely to remind us that, even in a small, planned, orderly, and successful "bilingual community" like Wales, there are competing ways of visualizing what "being bilingual" actually means.

\section{N O T E S}

*I am grateful to E. Wyn James, Adam Jaworski, Barbara Johnstone, and two anonymous reviewers for their very helpful comments on an earlier draft. This article was written in the context of a Finnish Academy grant, with Sari Pietikäinen as PI, for a project on Peripheral Multilingualism, based on comparative research on Corsican, Irish, Sami, and Welsh.

${ }^{1}$ In his published response to an early review of his book (Denzin \& Keller 1981), Goffman at one point, and in his own distinctive key, specifically mentions the importance of historical processes in framing:

Frames are a central part of a culture and are institutionalized in various ways. They are subject to change historically — a fact frequently noted in Frame Analysis even though details of historical change weren't much given, because of my own monumental ignorance in that connection. (Goffman 1981:63)

Other interpretations of Goffman's ideas have sometimes stressed the nonneutrality of framing processes, bringing a sharper political edge to frame analysis than in the original source. Entman (1993:52), for example, writes that "Typically frames diagnose, evaluate and prescribe." Moore \& Myerhoff (1977, responding to Goffman's 1974 publication) similarly comment that frames often attempt to fix or regularize an otherwise mutable cultural order.

${ }^{2}$ Iaith Pawb is available at http://wales.gov.uk/depc/publications/welshlanguage/iaithpawb/iaith pawbe.pdf?lang=en. A new policy document, Iaith Fyw: Iaith Byw ('A living language: A language for living') is currently out for consultation in connection with a new legal "measure" to be introduced in 2011. See http://wales.gov.uk/docs/drah/consultation/20101213alivinglanguageeng.pdf (these and other online documents last accessed 19 December 2010). The new document anticipates that 1500 private-sector businesses will have voluntary Welsh language policies in place by 2015 .

${ }^{3}$ The text of the Act is available at http://www.opsi.gov.uk/acts/acts1993/ukpga_19930038_en_1.

${ }^{4}$ Space precludes a more detailed discussion of revitalization programs and achievements to date; these are fully described in C. H. Williams (2008). For a recent collection of research papers and critical interpretations of bilingual Wales, see Coupland \& Aldridge (2009).

${ }^{5}$ The language-ideological history of this name is revealing. The Ordnance Survey map of 1875 marked Treorky but also a nearby stream named Nant (G)orky (nant means 'stream'). In 1916, a colliery (coal mine) was sunk nearby and named Abergorki Pit (aber means 'confluence of a water course'). As in the Cardiff street-name signs in Fig. 1 (where the Treorkey sign appears to be original, embedded in the fabric of the terrace of houses dating from 1910), spellings with $<\mathrm{k}>$ were normative in the early twentieth century, and $\langle\mathrm{ch}>$, corresponding to the Welsh velar fricative [x], had lapsed. Today, however, a different spelling, Treorchy, is the normative 'English' spelling, and Treorci is posited as the 'Welsh' 
equivalent. The new spelling Treorci renders the phonological shape of the anglicised second part of the name, with [k], using modern Welsh orthographic norms (there is no letter $\langle\mathrm{k}\rangle$ in Welsh). Treorchy is then taken to be 'English,' although it is pronounced similarly to the 'Welsh' form, again with [k], despite its Welsh-looking $<\mathrm{ch}>$. I analyzed anglicized pronunciation of Welsh place names in Cardiff in an earlier paper (Coupland 1984).

${ }^{6}$ Great Western Railway was the company responsible for running the train service between London and "the west" (of England, but taken at that time to include Wales) until 1947. The more recently added sign above it reads Caerdydd Canolog/Cardiff Central. The direction sign to Platforms 1 \& 2 is constructed in original tile work, while the lower sign is a newer, plastic-based addition.

${ }^{7}$ This trend is detectable via Google Maps as well as in public signage itself. Google now labels one of Cardiff's main shopping streets both Queen Street and Heol Y Frenhines, for example.

${ }^{8}$ The Welsh Language Board's Guidelines for Standardising Place-Names are available at http:// www.bwrdd-yr-iaith.org.uk/cynnwys.php?pID=109\&nID=2461\&langID=2.

${ }^{9}$ See http://cymuned.net.

${ }^{10}$ The slogan Nid yw Cymru ar werth has come through into wider circulation, for example, on social networking sites such as Facebook and Bebo.

${ }^{11}$ I am very grateful to Eddie Williams for his permission to reproduce this image, which features in his own analysis of language attitudes and politics in north Wales (E. Williams 2009:73).

${ }^{12}$ The image is discussed in Jaworski \& Thurlow (2010c); see also Thurlow \& Jaworski 2010:129ff. on "linguascaping the exotic."

${ }^{13}$ At the time of writing the text is still available online in the VisitWales pages targeting Irish tourists (http://www.visitwales.co.uk/ireland/).

${ }^{14}$ See http://www.visitwales.co.uk/about-wales-guide-to-wales-culture-people-and-language/languagewelsh-language/.

${ }^{15}$ I am very grateful to Wyn ap Gwilym and to cowbois, Gweithdai Penllyn, Stryd Y Plase, Y Bala, Gwynedd LL23 7SW, for supplying some of these images and for giving permission for them to be reproduced. Some of the images are available online at cowbois.com. I comment on some other cowbois shirt designs in Coupland (2010a).

${ }^{16}$ cowbois have also metaparodically invoked German in the slogan Vorsprung durch Celtique, parodying an Audi car advertisement slogan.

\section{R E F E R E N C E S}

Adam, Barbara (1998). Timescapes of modernity: The environment and invisible hazards. London: Routledge.

Aitchison, John, \& Harold Carter (2004). Spreading the word: The Welsh language 2001. Talybont: Y Lolfa. Backhaus, Peter (2007). Linguistic landscapes: A comparative analysis of urban multilingualism in Tokyo. Clevedon: Multilingual Matters.

(2009). Rules and regulations in linguistic landscaping: A comparative perspective. In Shohamy \& Gorter, 157-72.

Bauman, Richard, \& Charles Briggs (1990). Poetics and performance as critical perspectives on language and social life. Annual Review of Anthropology 19:59-88.

Ben-Rafael, Eliezwe, Elana Shohamy, \& Monica Barni (2010). Introduction. In Elana Shohamy, Eliezer Ben-Rafael, \& Monica Barni (eds.), Linguistic landscape in the city, xi-xxviii. Clevedon: Multilingual Matters.

Cooper, Robert L. (1989). Language planning and social change. Cambridge: Cambridge University Press.

Coulmas, Florian (2009). Linguistic landscaping and the seed of the public sphere. In Shohamy \& Gorter, 13-24.

Coupland, Nikolas (1984). Sociolinguistic aspects of place-names: Ethnic affiliation and the pronunciation of Welsh in the Welsh capital. In Wolfgang Viereck (ed.), Focus on: England and Wales. Varieties of English around the world G5, 29-43. Amsterdam: John Benjamins. 


\section{BILINGUALISM ON DISPLAY}

(2001). Dialect stylization in radio talk. Language in Society 3(3):345-75.

(2007). Style: Language variation and identity. Cambridge: Cambridge University Press.

(2010a). Welsh linguistic landscapes 'from above' and 'from below.' In Adam, Jaworski \& Crispin Thurlow (eds.), Semiotic landscapes: Text, image, space, 77-101. London: Continuum.

(2010b). Introduction: Social linguistics in the global era. In Nikolas Coupland (ed.), Handbook of language and globalization, 1-27. Malden, MA: Wiley Blackwell.

- \& Michelle Aldridge (eds.) (2009). Sociolinguistic and subjective aspects of Welsh in Wales and its diaspora. Thematic Issue (195) of International Journal of the Sociology of Language.

—,$\&$ Hywel Bishop (2006). Ideologising language and community in post-devolution Wales. In John Wilson \& Karyn Stapleton (eds.), Devolution and identity, 33-50. Aldershot: Ashgate.

-Betsy Evans, \& Peter Garrett (2006). Imagining Wales and the Welsh language: Ethnolinguistic subjectivities and demographic flow. Journal of Language and Social Psychology 25 (4):351-76.

—-Angie Williams, Betsy Evans, \& Peter Garrett (2005). Affiliation, engagement, language use and vitality: Secondary schools students' subjective orientations to Welsh and Welshness. International Journal of Bilingual Education and Bilingualism 8(1):1-24.

, \& Peter Garrett (2010). Linguistic landscapes, discursive frames and metacultural performance: The case of Welsh Patagonia. International Journal of the Sociology of Language 205:7-36.

_ $\quad$ \& Adam Jaworski (2004). Sociolinguistic perspectives on metalanguage: Reflexivity, evaluation and ideology. In Adam Jaworski, Nikolas Coupland, \& Darius Galasiński (eds.), Metalanguage: Social and ideological perspectives, 15-52. Berlin: Mouton de Gruyter.

Curtin, Melissa L. (2009). Languages on display: Indexical signs, identities and the linguistic landscape of Taipei. In Shohamy \& Gorter, 221-37.

Denzin, Norman K., \& Charles M. Keller (1981). Frame analysis reconsidered. Contemporary Sociology 10(1):52-60.

Dray, Susan (2010). Ideological struggles on signage in Jamaica. In Jaworski \& Thurlow, 102-22.

Eastman, Carol M., \& Roberta F. Stein (1993). Language display: Authenticating claims to social identity. Journal of Multilingual and Multicultural Development 14(3):187-202.

Entman, Robert M. (1993). Framing: Toward clarification of a fractured paradigm. Journal of Communication 43(4):51-58.

Goffman, Erving (1974). Frame analysis: An essay on the organization of experience. Cambridge, MA: Harvard University Press.

(1981). A reply to Denzin and Keller. Contemporary Sociology 10(1):60-68.

Gorter, Durk (ed.) (2006). Linguistic landscape: A new approach to multilingualism. Clevedon: Multilingual Matters.

Harley, J. B. (1971). Place-names on the early ordnance survey maps of England and Wales. The Cartographic Journal 8(2):91-104.

Heller, Monica (2002). Globalization and commodification of bilingualism in Canada. In David Block \& Deborah Cameron (eds.), Globalization and language teaching, 47-64. London: Routledge.

- (2003). Globalization, the new economy, and the commodification of language and identity. Journal of Sociolinguistics 7(4):473-92.

Jaworski, Adam (2010). Linguistic landscapes on postcards: Tourist mediation and the sociolinguistic communities of contact. Sociolinguistic Studies 4(3):469-594.

— \& Crispin, Thurlow (eds.) (2010a). Semiotic landscapes: Language, image, space. London: Continuum.

— \& - (2010b). Introducing semiotic landscapes. In Jaworski \& Thurlow, 1-40.

, \& _ (2010c). Language and the globalizing habitus of tourism: Towards a sociolinguistics of fleeting relationships. In Nikolas Coupland (ed.), The handbook of language and globalization, 255-86. Malden, MA: Wiley Blackwell.

Johnstone, Barbara (2009). Pittsburguese shirts: Commodification and the enregisterment of an urban dialect. American Speech 84(2):157-75. 
Kallen, Jeffrey L. (2010). Changing landscapes: Language, space and policy in the Dublin linguistic landscape. In Jaworski \& Thurlow, 41-58.

— \& Esther Ní Dhonnacha (2010). Language and inter-language in urban Irish and Japanese linguistic landscapes. In Shohamy et al., 19-36.

Kirshenblatt-Gimblett, Barbara (2004). Intangible heritage as metacultural production. Online: http:// www.nyu.edu/classes/bkg/web/heritage_MI.pdf.

Kress, Gunther, \& Theo van Leeuwen (2001). Multimodal discourse: The modes and media of contemporary communication. London: Arnold.

Landry, Rodrigue, \& Richard Y. Bourhis (1997). Linguistic landscape and ethnolinguistic vitality: An empirical study. Journal of Language and Social Psychology 16:23-49.

Leeman, Jennifer, \& Gabriella Modan (2009). Commodified language in Chinatown: A contextualized approach to linguistic landscape. Journal of Sociolinguistics 13(3):332-62.

Lewis, Peirce (1979). Axioms for reading the landscape. In D. W. Meinig (ed.), The interpretation of ordinary landscapes, 11-32. New York: Oxford University Press.

Lou, Jia (2009). Situating linguistic landscape in time and space: A multidimensional study of the discursive construction of Washington, DC Chinatown. Washington, DC: Georgetown University dissertation.

Merriman, Peter, \& Rhys Jones (2009). "Symbols of justice": The Welsh Language Society's campaign for bilingual road signs in Wales, 1967-1980. Journal of Historical Geography 35(2):350-75.

Moore, Donald (1986). The indexing of Welsh place-names. The Indexer 15(1):3-8.

Moore, Sally F., \& Barbara Myerhoff (eds.) (1977). Secular ritual. Amsterdam: Van Gorcum.

Morris-Jones, John (1928). Orgraff yr iaith Gymraeg [The orthography of the Welsh language]. Cardiff: University of Wales Board of Celtic Studies.

Musk, Nigel (2010). Bilingualisms-in-practice at the meso level: An example from a bilingual school in Wales. International Journal of the Sociology of Language 202:41-62.

Owen, Hywel Wyn (1998). The place-names of Wales. Cardiff: University of Wales Press and The Western Mail.

Pietikäinen, Sari (2010). Sámi language mobility: Scales and discourses of multilingualism in a polycentric environment. International Journal of the Sociology of Language 202:79-102.

Rampton, Ben (1995). Crossing. London: Longman.

- (2006). Language in late-modernity: Interaction in an Urban School. Cambridge: Cambridge University Press.

Reh, Mechthild (2004). Multilingual writing: A reader-oriented typology—with examples from Lira Municipality (Uganda). International Journal of the Sociology of Language 170:1-41.

Scheff, Thomas J. (2005). The structure of context: Deciphering Frame analysis. Sociological Theory 23 (4):368-85.

Schein, Richard H. (1997). The place of landscape: A conceptual framework for interpreting an American scene. Annals of the Association of American Geographers 87(4):660-80.

Scollon, Ron, \& Suzie Wong Scollon (2003). Discourses in place: Language in the material world. London: Routledge.

Shohamy, Elana; Eliezer Ben-Rafael; \& Monica Barni (eds.) (2010). Linguistic landscape in the city. Clevedon: Multilingual Matters.

— Routledge.

— \& Shoshi Waksman (2009). Linguistic landscape as an ecological arena: Modalities, meanings, negotiations, education. In Shohamy \& Gorter, 313-31.

Skutnabb-Kangas, Tove; \& Robert Phillipson (2010). The politics of global language extinction: From attrition to dispossession and linguistic genocide. In Nikolas Coupland (ed.), Handbook of language and globalization, 77-100. Malden, MA: Wiley Blackwell.

Spolsky, Bernard (2009). Prolegomena to a sociolinguistic theory of public signage. In Shohamy \& Gorter, 25-39. 


\section{BILINGUALISM ON DISPLAY}

Thurlow, Crispin, \& Adam Jaworski (2010). Tourism discourse: Language and global mobility. London: Palgrave Macmillan.

Urban, Greg (2001). Metaculture: How culture moves through the world. Minneapolis: University of Minnesota Press.

Urciuoli, Bonnie (1995). Language and borders. Annual Review of Anthropology 24:525-46.

Williams, Charlotte; Neil Evans; \& Paul O’Leary (eds.) (2003). A tolerant nation? Exploring ethnic diversity in Wales. Cardiff: University of Wales Press.

Williams, Colin H. (1990). The Anglicisation of Wales. In Nikolas Coupland (ed.), English in Wales: Diversity, conflict and change, 19-47. Clevedon: Multilingual Matters.

Press.

(2001). Language revitalization: Policy and planning in Wales. Cardiff: University of Wales Press.

(2008). Linguistic minorities in democratic context. Basingstoke: Palgrave Macmillan.

Williams, Eddie (2009). Language attitudes and identity in a North Wales town: "Something different about Caernarfon." International Journal of the Sociology of Language 195:63-92.

(Received 25 June 2010; revision received 24 December 2010; accepted 12 January 2011; final revision received 7 September 2011) 